УДК 316.4

DOI 10.52575/2712-746X-2021-46-2-286-297

\title{
Региональный рынок труда: вызовы, проблемы и кадровая политика
}

\author{
Тюриков А.Г. \\ Финансовый университет при Правительстве РФ, \\ Россия, 125993, ГСП-3, Москва, Ленинградский проспект, 49 \\ E-mail: agtyurikov@fa.ru
}

\begin{abstract}
Аннотация. Автор рассматривает глобальные противоречия и проблемы, обуславливающие развитие рынка труда и будущих профессий. Представлены методологические подходы и законодательная база, открывающие новые возможности для организации мониторинга рынка труда в современных условиях. По результатам проведенного экспертного опроса выявлены глобальные вызовы, стоящие перед региональными рынками труда. Описаны проблемы в основных сферах жизнедеятельности в регионах: политической, социальной и экономической. Как отмечает каждый второй из экспертов, наиболее остро перед региональными работодателями стоят три взаимосвязанные проблемы: высокая «текучесть» кадров, недостаток профессиональных компетенций сотрудников и дефицит высококвалифицированных кадров. Наибольшим спросом в материальной сфере региональной экономики сейчас пользуются специалисты в области информационных технологий (индекс востребованности - 0,61), на втором месте - «строительство» $(0,57)$ и затем грузоперевозки и складская логистика $(0,45)$. Среди образовательных организаций в регионах наиболее эффективны в решение кадровой политики, по мнению экспертов, региональные ВУЗы (индекс эффективности $0,65)$. Эксперты сошлись во мнении, что наиболее эффективный канал поиска работы в регионе - это «сарафанное радио» $(0,60)$, практически такой же эффективностью обладают онлайн сервисы по поиску работы $(0,59)$ и доски объявлений в интернете $(0,55)$.
\end{abstract}

Ключевые слова: региональный рынок труда, мониторинг, ключевые вызовы, работодатели, кадровая политика.

Благодарности: исследование выполнено по государственному заданию Финансовому университету при Правительстве Российской Федерации за счет бюджетных средств.

Для цитирования: Тюриков А.Г. 2021. Региональный рынок труда: вызовы, проблемы и кадровая политика. NOMOTHETIKA: Философия. Социология. Право, 46 (2): 286-297. DOI 10.52575/2712746X-2021-46-2-286-297

\section{Regional labor market: challenges, problems, personnel policy}

\author{
Alexander G. Tyurikov \\ Financial University under the Government of the Russian Federation, \\ 49 Leningradsky av., Moscow, GSP-3, 125993, Russia \\ E-mail: agtyurikov@fa.ru
}

\begin{abstract}
This article examines the global contradictions and problems that determine the development of the labor market and future professions. The article presents methodological approaches and legislative framework that open up new opportunities for organizing monitoring of the labor market in modern conditions. According to the results of the expert survey, the global challenges facing the regional labor markets are identified. The article describes the problems in the main spheres of life in the regions: political, social and economic, which include the low level of well-being of the population, low efficiency of officials, lack of highly qualified personnel, unemployment, underdevelopment of small and medium-sized businesses, low quality of medical services. As every second expert notes, the most acute problems facing regional employers are three interrelated problems: high" turnover " of personnel, lack of professional
\end{abstract}


competencies of employees and a shortage of highly qualified personnel. The greatest demand in the material sphere of the regional economy is now used by specialists in the field of information technology (demand index - 0.61), in second place - "construction" (0.5676) and then cargo transportation and warehouse logistics (0.45). Among the educational organizations in the regions, regional universities are the most effective in solving personnel policy, according to experts (the efficiency index is 0.65). Experts agreed that the most effective job search channel in the region is word of mouth (0.60), while online job search services (0.5960) and online bulletin boards (0.55) are almost as effective.

Acknowledgements: the study was carried out on a state assignment to the Financial University under the Government of the Russian Federation at the expense of budget funds.

Keywords: regional labor market, monitoring, key challenges, employers, personnel policy

For citation: Tyurikov A.G. 2021. Regional labor market: challenges, problems, personnel policy. NOMOTHETIKA: Philosophy. Sociology. Law series, 46 (2): 286-297 (in Russian). DOI 10.52575/2712746X-2021-46-2-286-297

\section{Введение}

Еще год назад сложно было представить, что рынок труда и будущих профессий так стремительно и радикально начнет меняться. Эта динамика обусловлена, с одной стороны, воздействием метавызовов - глобализации, цифровизации, пандемии, миграции, с другой стороны, готовностью прогнозировать и отвечать на эти вызовы на национальном, региональном и местном уровнях. При этом эксперты отмечают противоречие между уверенностью, что в ближайшее время цифровизация, искусственный интеллект и роботизация экономики подтолкнет к отмиранию десятки профессий и прогнозом того, что в России может образоваться дефицит квалифицированных кадров емкостью около 10 млн работников.

В этой связи особую значимость приобретают релевантность и валидность методов сбора и анализа данных о состоянии, структуре, динамике и содержанию рынка труда. Учитывая тот факт, что национальный рынок труда - это своеобразная и специфическая совокупность региональных и местных рынков, целесообразно ответить на ряд ключевых исследовательских вопросов: а) с какими вызовами, угрозами и проблемами столкнулись и будут иметь дело в ближайшей перспективе региональные рынки труда, б) на какие профессии и специальности есть и прогнозируется спрос в регионах, в) насколько эффективно функционируют на рыке труда основные актанты.

Проблематика анализа рынка труда и будущих профессий в последнее время актуализировалась в научном дискурсе зарубежных и российских исследователей. В фокусе исследований - поляризация рынка труда, рутинность работы, динамика содержания и структуры, ореол новых профессий [Goos, Manning, Salomons, 2012; Vom Lehn C, 2014; Гимпельсон, Капелюшников, 2015; Вишневская, Зудина, Лукьянова, 2017; Гимпельсон, Капелюшников, Рощин, 2017]; изменение характера рабочих мест, выявление роли и влияния технического прогресса на структурные изменения на рынке труда [Jaimovich, Siu, 2012; Cortes, 2014]; состояние и источники безработицы, вопросы ее регулирования и минимизации [Ахундова и др., 2004; Гимпельсон и др., 2012]; состояние и мобильность на российском рынке труда, методы анализа [Коровкин, 2001; Кривов, 2008; Агабекян, 2012].

\section{Объект и методы исследования}

С 2014 года в Российской Федерации с участием ведущих акторов нацинального и региональных рынков труда активно формируется национальная система квалификаций в соответствие с указами Президента Российской Федерации (Указ Президента РФ от 7 мая 2012 г. № 597; от 18 декабря 2016 г. № 676), Федеральных законов (ФЗ от 03.07.2016 № 238Ф3; от 29 декабря 2012 г. № 273-Ф3) и другими официальными документами. 
Согласно правительственным документам ряду государственных и некоммерческих организаций вменено проведение мониторинга рынка труда и будущих профессий. Под мониторингом понимается система регулярного социологического, статистического и динамического наблюдения за состоянием, структурой и динамикой рынка труда, описания его различных параметров при обязательном условии регулярного применения одних и тех же принципов выборки и одного и того же инструментария для сбора данных.

Данная статья в своем содержании и выводах опирается на результаты экспертного опроса $(\mathrm{n}=226)$, проведенного социологами Финансового университета при Правительстве РФ совместно с экспертным советом по вопросам развития региональной и муниципальной науки Комитета по науке и образованию ГД РФ в период с 15.03.2021 по 22.04.2021.

В опросе приняли участие специалисты из 26 регионов РФ: в сферах высшего и средне-специального образования, государственного и муниципального управления, операторы-хэдхантеры, работодатели и другие.

При этом исследователи отдавали себе отчет, что какие бы конкретные методы не выбрал социолог, он должен руководствоваться фундаментальным принципом социологического мышления, точно сформулированным А. Туреном: «Предметом социологии является объяснение поведения действующих лиц посредством социальных отношений, в которых они оказываются». Наивно думать, что «можно... объяснять поведение уровнем заработной платы, типом жилища или состоянием техники. Очевидно, нужно сначала превратить эти “ситуации” в общественные отношения и, прежде всего, в уровни участия» [Турен, 1998. c. 67].

\section{Материалы и результаты}

На первом этапе экспертов попросили описать глобальные вызовы, с которыми столкнулись в настоящий момент регионы. В данных, представленных в табл. 1, проранжированы основные глобальные вызовы, на которые в первую очередь обращают внимание эксперты.

Таблица 1

Table 1

Глобальные вызовы, стоящие перед регионами

Global challenges facing the regions

\begin{tabular}{|l|c|}
\hline \multicolumn{1}{|c|}{ Вызовы } & Ранг \\
\hline Социальное неравенство & 1 \\
\hline Деиндустриализация региональной экономики & 2 \\
\hline $\begin{array}{l}\text { Низкое развитие социальной сферы в целом (финансирование, } \\
\text { инфраструктра) }\end{array}$ & 3 \\
\hline Неблагоприятный инвестиционный климат & 4 \\
\hline Экономический кризис & 5 \\
\hline Не благоприятная политико-экономическая ситуация в мире & 6 \\
\hline Утечка мозгов, эмиграция населения & 7 \\
\hline $\begin{array}{l}\text { Нестабильная внутриполитическая ситуация, рост протестных } \\
\text { настроений }\end{array}$ & 8 \\
\hline Цифровизация экономики & 9 \\
\hline Угроза военных конфликтов & 10 \\
\hline
\end{tabular}


Анализ представленных данных позволяет выделить пятерку наиболее значимых вызовов, на которые необходимо дать ответ на региональном уровне. Это социальное неравенство, деиндустриализация региональных экономик, низкий уровень развития социальной сферы, неблагоприятный инвестиционный климат и экономический кризис.

На втором этапе эксперты оценивали вызовы в основных сферах жизнедеятельности регионов. Так, к вызовам в политической сфере (табл. 2) отнесены: неэффективная деятельность чиновников, нестабильная политическая ситуация и низкий уровень доверия к власти.

Таблица 2

Table 2

Вызовы в политической сфере, стоящие перед регионами

Political challenges facing the regions

\begin{tabular}{|l|c|}
\hline \multicolumn{1}{|c|}{ Вызовы } & Ранг \\
\hline Неэффективная работа чиновников & 1 \\
\hline Нестабильная политическая ситуация & 2 \\
\hline Низкий уровень доверия к власти & 3 \\
\hline Угроза военных конфликтов & 4 \\
\hline Отсутствие политического плюрализма & 5 \\
\hline
\end{tabular}

В социальной сфере на первые места эксперты поставили следующие вызовы: социальное неравенство, низкий уровень жизни и безработицу, прежде всего, в молодежной среде (табл. 3).

Вызовы в социальной сфере, стоящие перед регионами

Social challenges facing the regions

\begin{tabular}{|l|c|}
\hline \multicolumn{1}{|c|}{ Вызовы } & Ранг \\
\hline Социальное неравенство & 1 \\
\hline Низкий уровень жизни & 2 \\
\hline Безработица & 3 \\
\hline Слабая помощь социально-незащищенным группам & 4 \\
\hline Низкие зарплаты & 5 \\
\hline Низкое качество медицинских услуг & 6 \\
\hline $\begin{array}{l}\text { Низкий уровень развития социальной сферы в целом } \\
\text { (финансирование, инфраструктура) }\end{array}$ & 7 \\
\hline
\end{tabular}

В экономической сфере эксперты отмечают в первую очередь вызовы, обусловленные неразвитостью малого и среднего бизнеса, низким уровнем благосостояния населения и безработицей (табл. 4). При этом обращает на себя внимание тот факт, что безработица занимает ведущую позицию как в социальной, так и в экономической сфере. 
Вызовы в экономической сфере, стоящие перед регионами

Economic challenges facing the regions

\begin{tabular}{|l|c|}
\hline \multicolumn{1}{|c|}{ Вызовы } & Ранг \\
\hline Не развит малый и средний бизнес & 1 \\
\hline Низкий уровень благосостояния населения & 2 \\
\hline Безработица & 3 \\
\hline Неблагоприятный инвестиционный климат & 4 \\
\hline Деиндустриализация & 5 \\
\hline Инфляция & 6 \\
\hline Экономический кризис & 7 \\
\hline Цифровизация экономики и инновационное развитие & 8 \\
\hline Слабое развитие инфраструктуры & 9 \\
\hline
\end{tabular}

Среди основных проблем, которые наиболее актуальны для регионального развития в целом и для рынка труда в частности, эксперты выделили следующие (по мере убывания весов):

- крайне низкий уровень доходов населения;

- безработицу;

- неразвитость малого и среднего бизнеса в регионах;

- слабую помощь социально-незащищенным группам населения;

- низкое качество медицинских услуг;

- неэффективную работу чиновников и коррупцию.

Далее экспертов просили выделить и описать проблемы, с которыми в настоящий момент времени имеют дело работодатели (рис. 1).

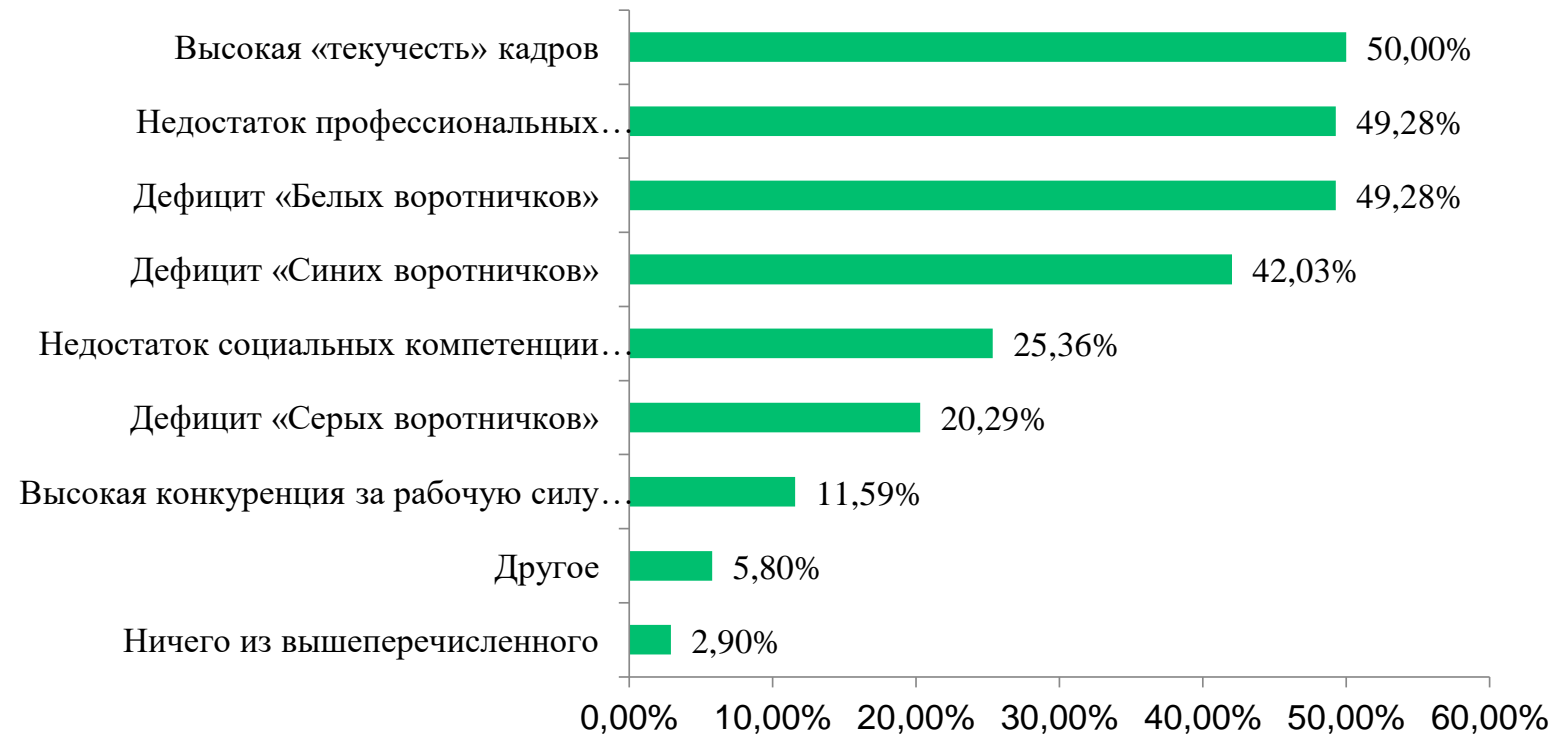

Рис. 1. Проблемы работодателей на рынке труда

Fig. 1. Problems of employers in the labor market 
Как отмечает каждый второй из экспертов наиболее остро перед региональными работодателями стоят три взаимосвязанные проблемы: 1) высокая «текучесть» кадров; 2) недостаток профессиональных компетенций сотрудников; 3) дефицит высококвалифицированных кадров.

Главными лимитирующим факторами развития рынка труда по мнению экспертов являются экономический фактор (средний ранг - 3.9), административный фактор $(3,6)$ и социально-демографический фактор $(3,3)$ (рис. 2).

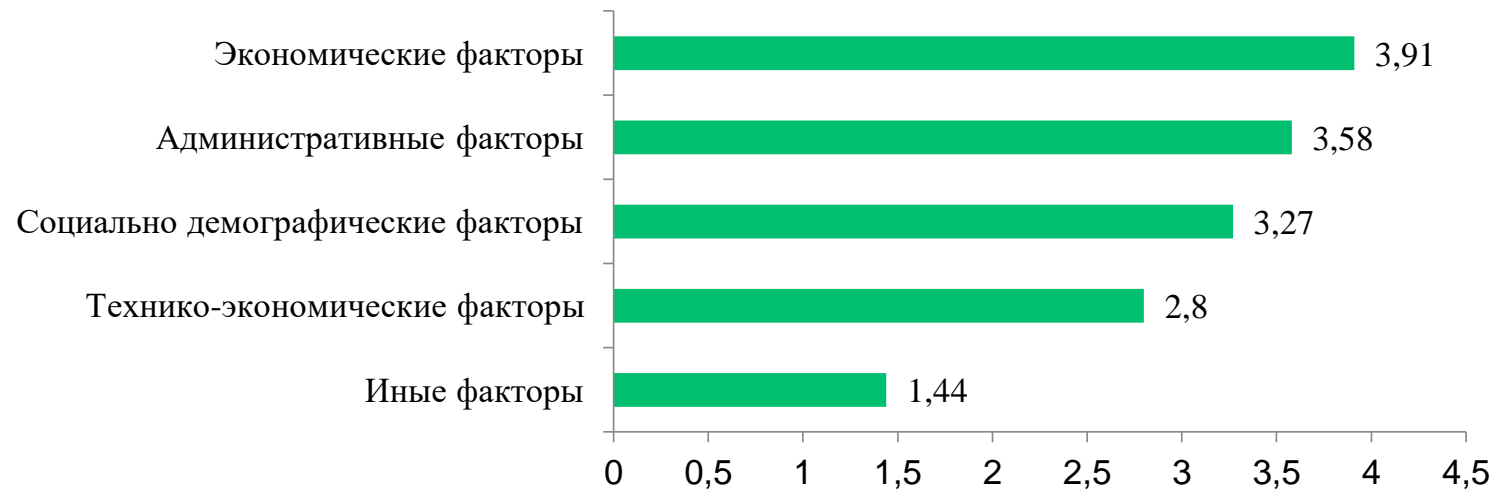

Рис. 2. Лимитирующие факторы развития регионального рынка труда

Fig. 2. Limiting factors of the regional labor market development

Наиболее сильно на региональный рынок труда влияет общая динамика неблагоприятной экономической ситуации в стране.

Экспертам предлагалось определить - а с какими актуальными проблемами сталкивается наемный работник на региональном рынке труда (см рис. 3) в их регионе.

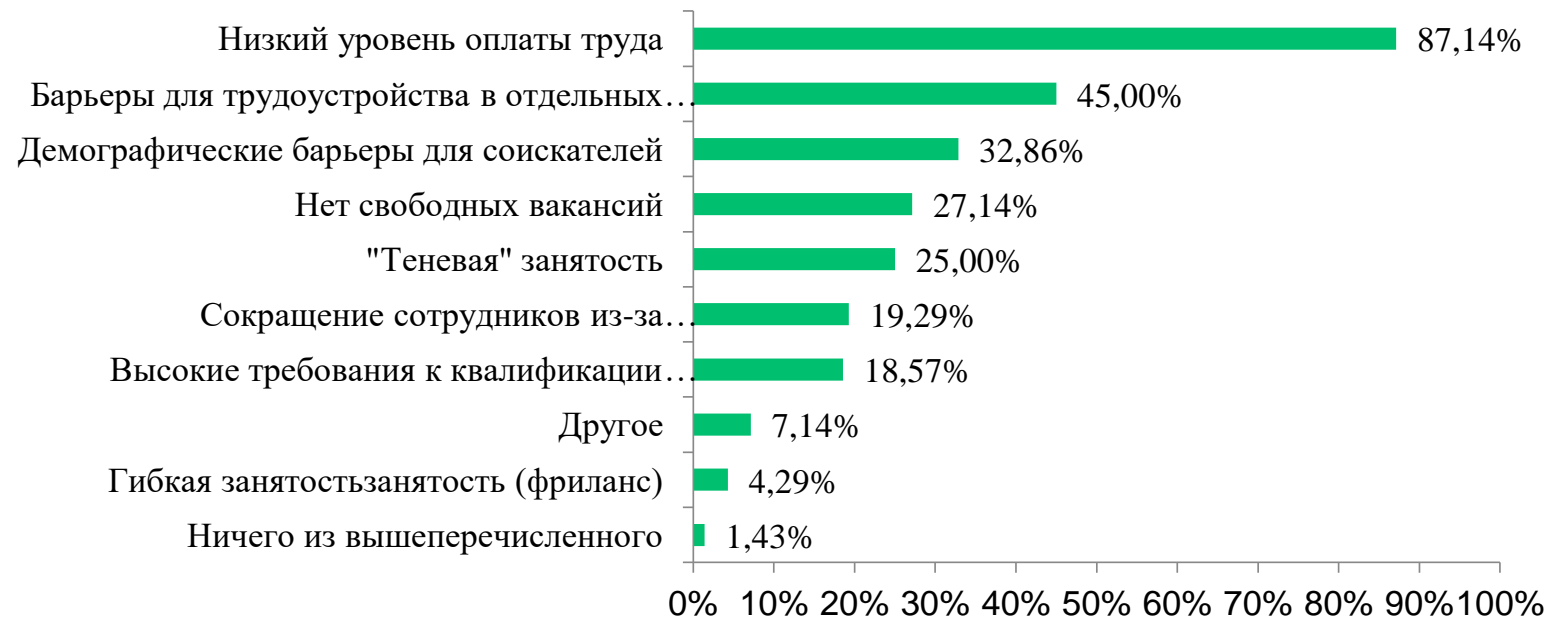

Рис. 3. Проблемы наемных работников на рынке труда

Fig. 3. Problems of employees in the labor market

С точки зрения наемного работника особую остроту имеет проблема низкого уровня оплаты труда. О ней говорят 87,1 \% экспертов. Особые опасения вызывает тот факт, что 45 \% экспертов заявили о наличии высоких барьеров для трудоустройства в определенных отраслях экономики, как об одной из важнейших проблем регионального рынка труда. Также треть экспертов (32,7 \%) обеспокоена наличием непреодолимых демографических 
барьеров (по признаку полу, возраста, национальности и т. д.) существующих на просторах регионального рынка труда.

Каков сегодня спрос на рабочую силу на региональном рынке труда по мнению экспертов? Экспертов просили оценить спрос в материальной и нематериальной сферах деятельности. Так, в отношении востребованности кадров в отдельных отраслях материальной сферы экономики региона полученные результаты представлены на рис. 4.

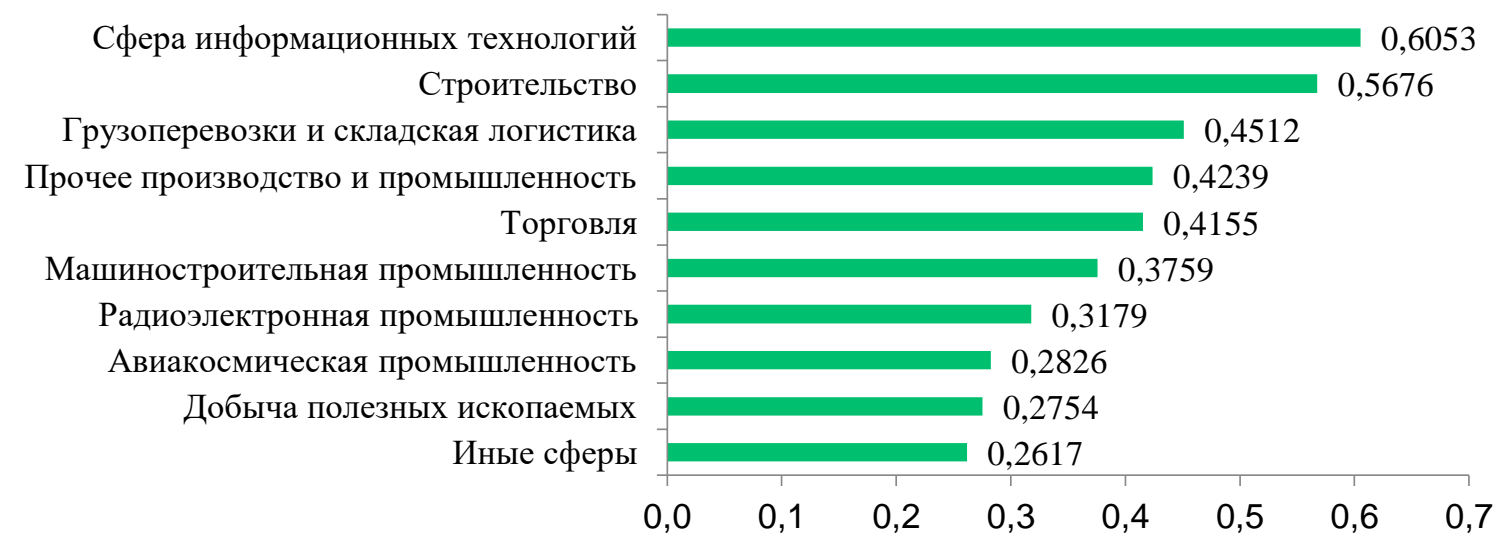

Рис. 4. Спрос на рабочую силу в материальной сфере региональной экономики

Fig. 4. Demand for labor in the material sphere of the regional economy

Согласно общероссийской тенденции наибольшим спросом в материальной сфере региональной экономики сейчас пользуются специалисты в области информационных технологий (индекс востребованности $\left.{ }^{1}-0,6053\right)$. На второй строчке - «Строительство» $(0,5676)$. Затем грузоперевозки и складская логистика $(0,4512)$.

Среднюю группу составляют прочие сферы производства и промышленности $(0,4239)$, торговля $(0,4155)$ и машиностроительная промышленность $(0,3759)$.

Наиболее низкий спрос на специалистов в регионах наблюдается в сферах добычи полезных ископаемых $(0,2754)$, авиакосмической и радиоэлектронной промышленностей $(0,2826$ и 0,3179 соответственно). Возникает гипотеза, что такой уровень востребованности обусловлен либо слабой развитостью данной сферы в регионах, либо наличием серьезных барьеров для трудоустройства.

В сфере нематериальной экономики эксперты выделили следующие отрасли с высокой потребностью в кадрах (рис. 5): во-первых, высоко востребованы специалисты в сфере здравоохранения $(0,8050)$, во-вторых, в сфере образования $(0,6925)$, в-третьих, в науке и научных исследованиях $(0,5626)$.

Средние позиции по востребованности заняли такие сферы, как физическая культура и социальное обеспечение $(0,5)$, ЖКХ $(0,4786)$, культура и искусство $(0,4004)$ и органы государственного управления (0,3903).

${ }^{1}$ Индекс востребованности варьируется от «0» до «1». Соответственно «0» означает низкую востребованность, а «1» высокую. Расчет индекса производится на основе ответов экспертов на вопрос «Оцените по 5-ти бальной шкале потребность в кадрах, которая сегодня наблюдается в следующим сферах?» по формуле $\frac{x_{5} * 1+x_{4} * 0,75+x_{3} * 0,5+x_{2} * 0,25+x_{1} * 0}{\mathrm{n}}$. Где $1 ; 0,75 ; 0,5 ; 0,25 ; 0$ - это весовые значения, соответствующие каждому из пяти значений шкалы, $\mathrm{x}$ - количество респондентов, выбравших данный вариант ответа, $\mathrm{n}$ - общее число опрошенных экспертов. 


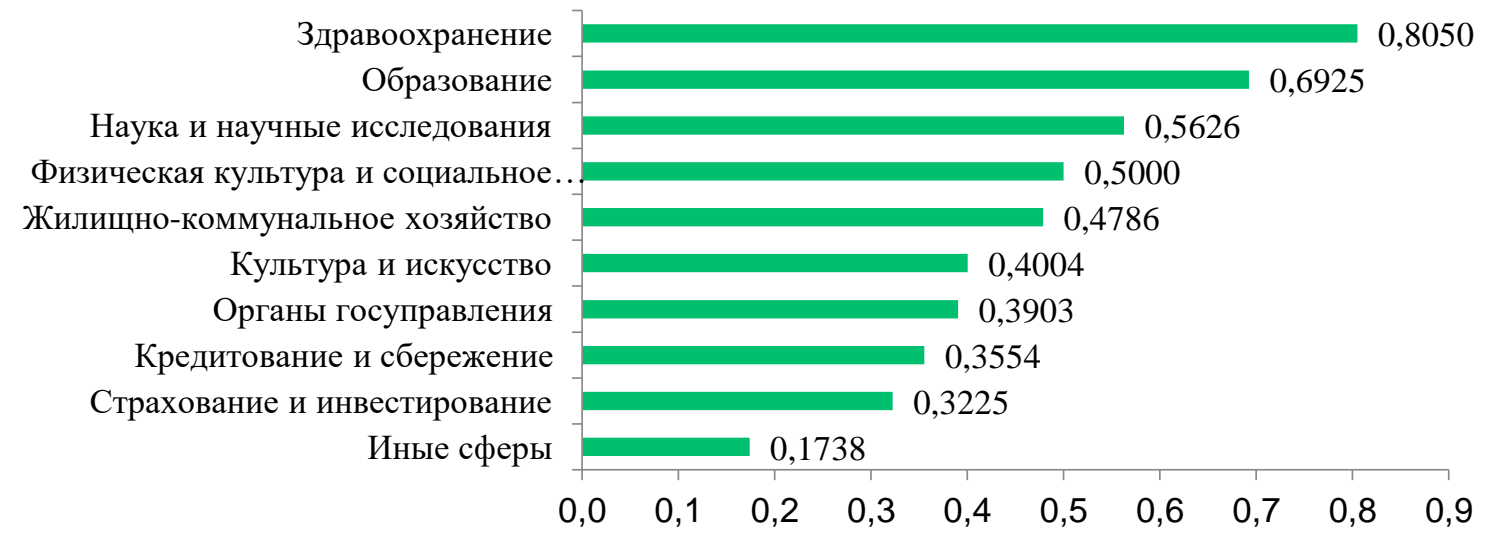

Рис. 5. Спрос на рабочую силу в нематериальной сфере региональной экономики Fig. 5. Demand for labor in the intangible sphere of the regional economy

Интересное наблюдение, по мнению экспертов специалисты финансового сектора, в частности в сферы кредитования и сбережения, страхования и инвестирования оказываются не востребованными в регионах $(0,3554$ и 0,3225 соответственно).

В первую очередь на баланс спроса и предложения на рынке труда влияют образовательные организации, так как они в «идеальном случае» отталкиваясь от запросов рынка формируют образовательные программы и готовят специалистов, востребованных на рынке. От эффективности их деятельности напрямую зависит решение обозначенных экспертами выше проблем, связанных с дефицитом высококвалифицированных кадров, не достатком у сотрудников профессиональных навыков и компетенций.

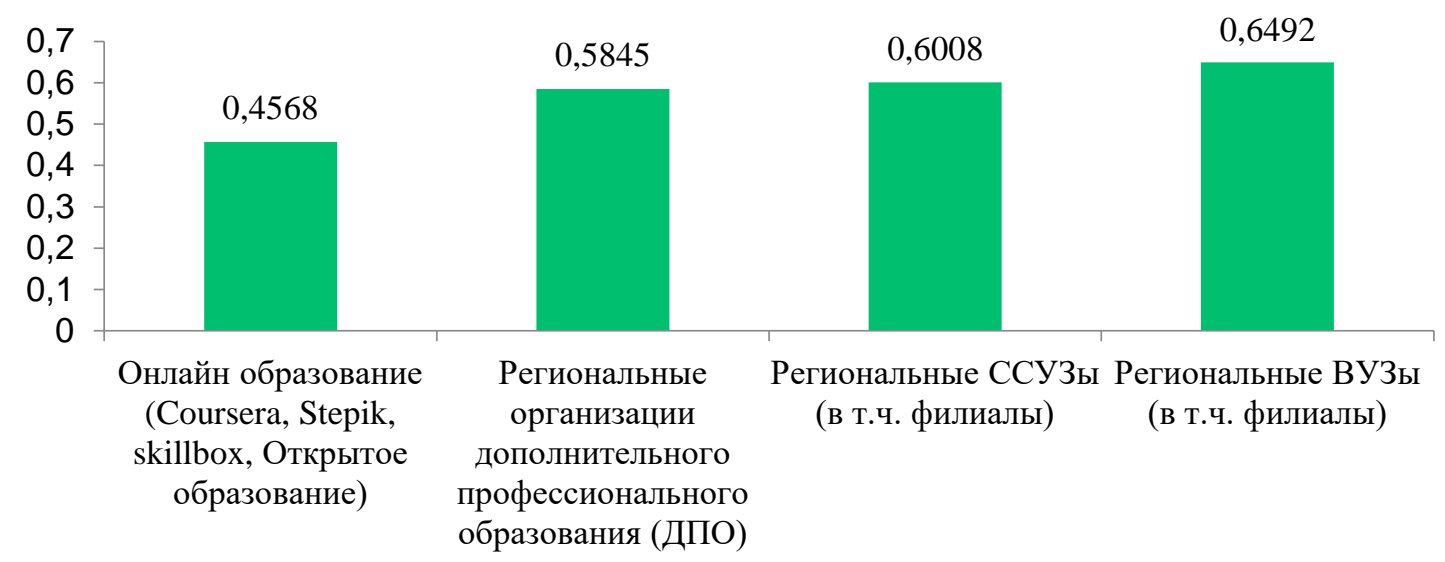

Рис. 6. Эффективность деятельности образовательных организаций в отношении кадрового обеспечения региона

Fig. 6. The effectiveness of educational organizations in terms of staffing in the region

Наиболее эффективны в решение кадровых проблем, по мнению экспертов, региональные ВУЗы (индекс эффективности $\left.{ }^{1}-0,6492\right)$ (рис.6). Вместе с тем полученные результаты вызывают вопрос: как региональные вузы могут быть столь эффективны, если среди

${ }^{1}$ Методика расчета индекса эффективности аналогична методике расчета индекса востребованности (см. сноску № 1). Исключение составляет только формулировка вопроса «Оцените эффективность деятельности образовательных организаций с точки зрения решения проблем дефицита кадров на региональном рынке труда? (где «1» - низкая эффективность, а «5» - высокая эффективность)» 
проблем рынка труда ключевое положение занимает проблемы дефицита высококвалифицированных сотрудников (по сути выпускников этих ВУЗов) и не соответствия профессиональных компетенций сотрудников требованиям рынка?

В оценки эффективности деятельности института дополнительного профессионального образования эксперты склонны считать, что данный вид образования является менее эффективным $(0,5845)$, чем классическая высшая школа и среднее профессиональное образование $(0,6008)$.

По мнению экспертов, не достигли еще пока своей должной эффективности недавно появившиеся площадки оказывающие услуги онлайн-образования. Их индекс эффективности существенно ниже прочих и составляет 0,4568.

Вторым ключевым посредником на рынке труда являются организации и площадки, обеспечивающие связь между работниками и работодателями посредством размещения вакансий о работе и резюме соискателей. Экспертам предоставлялась возможность оценить, насколько тот или иной канал трудоустройства эффективен с точки зрения решения кадровых проблем региона (рис. 7).

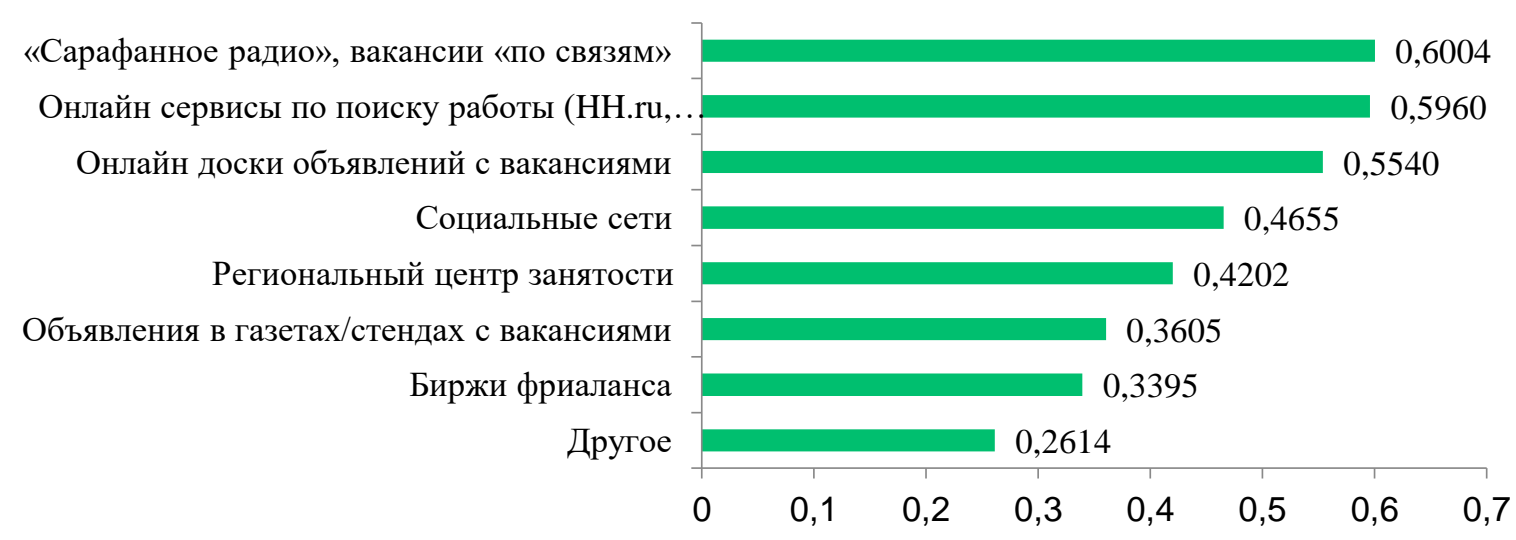

Рис. 7. Эффективность каналов трудоустройства в регионе

Fig. 7. Effectiveness of employment channels in the region

Опрошенные эксперты сошлись во мнении, что наиболее эффективный канал поиска работы в регионе - «сарафанное радио» $(0,6004)$ - поиск вакансий или новых сотрудников через родственников, друзей и знакомых. Практически такой же эффективностью обладают онлайн сервисы по поиску работы $(0,5960)$ и доски объявлений в интернете $(0,5540)$.

Инновационный способ поиска временной рабочей силы - биржи фриланса занял последние место по эффективности на региональном рынке труда $(0,3395)$. Предпоследнее место разделяют традиционные каналы поиска работы - объявления в газетах/стендах $(0,3605)$ и услуги регионального центра занятости $(0,4202)$.

\section{Обсуждение и выводы}

Результаты исследования были обсуждены на заседании экспертного совета по вопросам развития региональной и муниципальной политики Комитета по науке и образованию ГД РФ 22 апреля 2021 года в Финуниверситете. В фокусе дискуссии оказались как вызовы и проблемы развития региональных рынков труда, так и ресурсное обеспечение, кадровая политика, стратегии и программы развития регионов. К основным глобальным вызовам, стоящим перед регионами, экспертное сообщество относит: вызов национальной и региональной неопределенности, вызов разнообразия, вызов сложности и вызов, связанный с нелинейностью развития. 
На региональном рынке труда сегодня самыми острыми являются три взаимосвязанные проблемы: высокая текучесть кадров, низкие профессиональные компетенции сотрудников и дефицит высококвалифицированных работников, что в свою очередь предопределяет содержание и «сыгранность» кадровой политики на уровне региона, муниципалитетов, предприятий и образовательной среды.

На одно из ведущих мест в кадровой политике выходит проблема профориентации, ее содержания и методов исследования. В этом плане целесообразно организовать и провести серию количественных и качественных исследований по направлениям:

- анализ действующих практик профориентации и трудоустройства в контексте региональных приоритетов;

- оценка эффективности системы профориентации на занятость в перспективных сферах: сильные и слабые стороны системы, направления и перспективы совершенствования.

Сегодня линейное решение, когда рынок послал сигнал, а вузы среагировали через три - пять лет, уже не работает - все гораздо сложнее, динамичнее, непредсказуемее. Поэтому на первый план выходят предрасположенность, подготовленность и готовность к изменениям, софт скилз, умение меняться, «добывать» релевантную ситуации и человеческому потенциалу информацию на рынке труда.

\section{Список источников}

1. Указ Президента Российской Федерации от 7 мая 2012 г. № 597 «О мероприятиях по реализации государственной социальной политики».

2. Указ Президента Российской Федерации от 18 декабря 2016 г. № 676 «О внесении изменений в Положение о Национальном совете при Президента РФ по профессиональным квалификациям».

3. Федеральный закон от 03.07.2016 № 238-Ф3 «О независимой оценке квалификации».

4. Федеральный закон от 29 декабря 2012 № 273-ФЗ «Об образовании в Российской Федерации».

\section{Список литературы}

1. Агабекян Р.Л. 2012. Особенности трансформации российских рынков труда по видам экономической деятельности. Вестник Адыгейского государственного университета. Серия 5: Экономика. № 2. URL: https://cyberleninka.ru/article/n/osobennosti-transformatsii-rossiyskih-rynkov-trudapo-vidam-ekonomicheskoy-deyatelnosti (дата обращения: 10.04.2021).

2. Ахундова О.В., Коровкин А.Г., Королев И.Б., Подорванова Ю.А. 2004. Безработица на российском рынке труда: отраслевой аспект. Научные труды: Институт народнохозяйственного прогнозирования PAH. № 2. URL: https://cyberleninka.ru/article /n/bezrabotitsa-na-rossiyskom-rynketruda-otraslevoy-aspekt (дата обращения: 10.04.2021).

3. Гимпельсон В.Е., Капелюшников Р.И., Рыжикова 3.А. 2012. Движение рабочих мест в российской экономике: в поисках созидательного разрушения. Нац. исслед. ун-т «Высшая школа экономики». М., Изд. дом Высшей школы экономики. URL: https://www.hse.ru /data/2012/04/05/1251237418/WP3_2012_03.pdf (дата обращения: 12.04.2021).

4. Вишневская Н.Т., Зудина А.А., Лукьянова А.Л. 2017. Профессии на российском рынке труда. М., Изд. дом Высшей школы экономики. 159, [1] c. URL: https://publications.hse.ru/mirror/pubs/share/folder/kd714ks118/direct/205016549.pdf (дата обращения: 12.04.2021).

5. Гимпельсон В.Е., Капелюшников Р.И. 2015. «Поляризация» или «улучшение»? Эволюция структуры рабочих мест в России в 2000-е годы. М., Изд. дом Высшей школы экономики. 100 c. URL: https://www.hse.ru/data/2015/02/27/1091543859/WP3_2015_01_.pdf. (дата обращения: 10.04.2021).

6. Капелюшников Р.И. 2006. Структура российской рабочей силы: особенности и динамика. — М., ГУ ВШЭ. 64 c. URL: https://www.hse.ru/data/2010/05/04/1216408194/WP3 _2006_04.pdf (дата обращения: 08.04.2021). 
7. Кривов Е. 2008. Новые технологии исследования кадрового рынка. Анализ динамики кадрового рынка. Управление персоналом. № 15. URL: http://www.top-personal.ru/issue.html?1701. (дата обращения: 08.04.2021).

8. Коровкин А.Г. 2001. Динамика занятости и рынка труда: вопросы макроэкономического анализа и прогнозирования. М., ООО "МАКС Пресс", 320 с.

9. Доклад Центра трудовых исследования и Лаборатории исследования рынка труда НИУ ВШЭ. Российский рынок труда: тенденции, институты, структурные изменения / Под редакцией В. Гимпельсона, Р. Капелюшникова и С. Рощина. 2017. C. 48-58. URL: https://lirt.hse.ru/data/2017/03/21/1170068107/Doklad_trud.pdf. (дата обращения: 12.04.2021).

10.Турен А. 1998. Возвращение человека действующего. Очерк социологии. М., Научный мир. 204 с.

11.Cortes G., Jaimovich N., Nekarda C., Siu H. 2014. The Micro and Macro of Disappearing Routine Jobs: A Flows Approach. URL: http://www.nber.org/papers/w20307.pdf (дата обращения: 05.04.2021).

12.Goos M, Manning A., Salomons A. 2012. Explaining Job Polarization: The Roles of Technology, Offshoring and Institutions. URL: https://papers.ssrn.com/sol3/papers.cfm?abstract_id=1983952 (дата обращения: 05.04.2021).

13. Vom Lehn C. 2014. Labor Market Polarization, the Decline of Routine Work, and Technological Change: A Quantitative Analysis. URL: https://www.economicdynamics.org /meetpapers/2015/paper_151.pdf. (дата обращения: 06.04.2021).

14.Jaimovich N., Siu H. 2012. The Trend is The Cycle: Job Polarization and Jobless Recoveries. URL: http://www.nber.org/papers/w18334.pdf. (дата обращения: 05.04.2021).

\section{References}

1. Aghabekyan R.L. 2012. Features of the transformation of Russian labor markets by type of economic activity. Bulletin of the Adyghe State University. Series 5: Economics. No. 2. URL: https://cyberleninka.ru/article/n/osobennosti-transformatsii-rossiyskih-rynkov-truda-po-vidamekonomicheskoy-deyatelnosti (accessed 10.04.2021).

2. Akhundova O.V., Korovkin A.G., Korolev I.B., Podorvanova Yu.A. 2004. Unemployment in the Russian labor market: the sectoral aspect. Scientific works: Institute of National Economic Forecasting of the Russian Academy of Sciences. No. 2. URL: https://cyberleninka.ru /article/n/bezrabotitsa-narossiyskom-rynke-truda-otraslevoy-aspekt (accessed 10.04.2021).

3. Gimpelson V.E., Kapelyushnikov R.I., Ryzhikova Z.A. 2012. The Movement of Jobs in the Russian Economy: In Search of Creative Destruction. Nat. issled. University Higher School of Economics. M., Izd. house of the Higher School of Economics. URL: https://www.hse.ru/data/2012/04/05/1251237418/WP3_2012_03.pdf (accessed 12.04.2021).

4. Vishnevskaya N.T., Zudina A.A., Lukyanova A.L. 2017. Professions in the Russian Labor Market. Nat. issled. University Higher School of Economics. - M., Ed. House of the Higher School of Economics. 159 p., [1] URL: https://publications.hse.ru/mirror/pubs/share/folder/kd714ks118 /direct/205016549.pdf (accessed 12.04.2021).

5. Gimpelson V.E., Kapelyushnikov R.I. 2015. "Polarization" or "Improvement"? Evolution of the structure of jobs in Russia in the 2000s. Moscow: Ed. house of the Higher School of Economics. 100 p. URL: https://www.hse.ru/data/2015/02/27/1091543859/WP3_2015_01_.pdf. (accessed 10.04.2021).

6. Kapelyushnikov R.I. 2006. The structure of the Russian labor force: features and dynamics. M., GU HSE. 64 p. URL: https://www.hse.ru/data/2010/05/04/1216408194/WP3_2006_04.pdf (accessed 08.04.2021).

7. Krivov E. 2008. New Technologies for Researching the Personnel Market. Analysis of the dynamics of the personnel market. Personnel Management. No. 15. URL: http://www.toppersonal.ru/issue.html?1701 (accessed 08.04.2021).

8. Korovkin A.G. 2001. Employment and Labor Market Dynamics: Issues of Macroeconomic Analysis and Forecasting. M., LLC "MAKS Press", 320 p.

9. Report of the Center for Labor Research and the Labor Market Research Laboratory of the Higher School of Economics. The Russian labor market: trends, institutions, structural changes / Edited by V. Gimpelson, R. Kapelyushnikov and S. Roshchin. 2017. P. 48-58. URL: https://lirt.hse.ru/data/2017/03/21/1170068107/Doklad_trud.pdf (accessed 12.04.2021). 
10. Touraine A. 1998. The return of the acting person. Essay of sociology. M., Scientific world. 204 p.

11. Cortes G., Jaimovich N., Nekarda C., Siu H. 2014. The Micro and Macro of Disappearing Routine Jobs: A Flows Approach. URL: http://www.nber.org/papers/w20307.pdf (accessed 05.04.2021)

12. Goos M, Manning A., Salomons A. 2012. Explaining Job Polarization: The Roles of Technology, Offshoring and Institutions. URL: https://papers.ssrn.com/sol3/papers.cfm? abstract_id=1983952 (accessed 05.04.2021)

13. Vom Lehn C. 2014. Labor Market Polarization, the Decline of Routine Work, and Technological Change: A Quantitative Analysis. URL: https://www.economicdynamics.org /meetpapers/2015/paper_151.pdf (accessed 06.04.2021)

14. Jaimovich N., Siu H. 2012. The Trend is The Cycle: Job Polarization and Jobless Recoveries. URL: http://www.nber.org/papers/w18334.pdf (accessed 05.04.2021)

\section{СВЕДЕНИЯ ОБ АВТОРЕ}

Тюриков Александр Георгиевич, доктор социологических наук, профессор, руководитель Департамента социологии Факультета социальных наук и массовых коммуникаций Финансового университета при Правительстве Российской Федерации, Москва, Россия

\section{INFORMATION ABOUT THE AUTHOR}

Alexander G. Tyurikov, Doctor of Sociology, Professor, Head of the Department of Sociology, Faculty of Social Sciences and Mass Communications, Financial University under the Government of the Russian Federation, Moscow, Russia 